\title{
Descrição de três espécies novas de Porphyrochroa Melander (Diptera, Empididae) da Bacia Amazônica, Brasil
}

\author{
Mirian Nascimento Mendonça ${ }^{1}$, José Albertino Rafael $^{2,3} \&$ Rosaly Ale-Rocha ${ }^{2}$
}

\begin{abstract}
${ }^{1}$ Estudante de Mestrado do Programa Pós-graduação em Entomologia do INPA. Bolsista do CNPq. mirianbiotec@yahoo.com.br ${ }^{2}$ Instituto Nacional de Pesquisas da Amazônia, Coordenação de Entomologia, Caixa Postal 478, 69011-970 Manaus-AM, Brasil jarafael@inpa.gov.br; alerocha@inpa.gov.br

${ }^{3}$ Bolsista produtividade do $\mathrm{CNPq}$
\end{abstract}

\begin{abstract}
Description of three new species of Porphyrochroa Melander (Diptera, Empididae) from the Amazon Basin, Brazil. Porphyrochroa Melander, 1928 is recorded for the first time in the Brazilian Amazon Basin and three new species are described and illustrated, namely: P. elongata sp. $\mathrm{n}$. (Amazonas and Acre), P. hipandriociliaris sp. $\mathrm{n}$. (Amazonas) and P. vidali sp. n. (Roraima and Amazonas).
\end{abstract}

KEYWORDS. Amazon; biodiversity; Empidinae; news records; taxonomy.

RESUMO. Descrição de três espécies novas de Porphyrochroa Melander (Diptera, Empididae) da Bacia Amazônica, Brasil Porphyrochroa Melander, 1928 é registrado pela primeira vez na Bacia Amazônica brasileira e três espécies novas são descritas e ilustradas, $P$. elongata sp. n. (Amazonas e Acre), P. hipandriociliaris sp. n. (Amazonas) e P. vidali sp. $\mathrm{n}$. (Roraima e Amazonas).

PALAVRAS-CHAVE. Amazônia; biodiversidade; Empidinae; novos registros; taxonomia.

O gênero Porphyrochroa Melander, 1928 foi erigido com base em Sciodromia palliata (Coquillett, 1902), espécie-tipo do gênero e incluído em Empidinae (Melander 1928). Esta subfamília é considerada grupo-irmão de Hemerodromiinae + Clinocerinae (Sinclair \& Cumming 2006).

As espécies do gênero possuem distribuição Neotropical, sendo registrado, até o momento, para México, República Dominicana, Panamá, Guiana, Peru, Brasil e Bolívia. O gênero foi negligenciado ao longo do tempo até que Smith (1967) o sinonimizou com Macrostomus Wiedemann, 1817 baseandose em caracteres que hoje são considerados sinapomorfias de ambos os gêneros. Foi revalidado por Rafael (2001) e, posteriormente, várias espécies, originalmente nos gêneros Rhamphomyia Meigen, 1822 e Macrostomus, foram transferidas para o gênero por Rafael \& Cumming (2004). Porphyrochroa atualmente possui 32 espécies e sua monofilia está baseada em várias sinapomorfias, a saber: tergito 8 do macho com cerdas restritas à área póstero-dorsal (espalhadas por todo tergito em Macrostomus e outros gêneros próximos); tergito 7 do macho com protuberância póstero-ventral (ausente em Macrostomus e outros gêneros próximos); abdômen azul ou azul-esverdeado com reflexos metálicos (Macrostomus e outros gêneros próximos sem este padrão) (Rafael \& Cumming 2004).

\section{MATERIALEMÉTODOS}

O material estudado pertence à Coleção de Invertebrados do INPA e foi coletado principalmente com armadilhas de interceptação de vôo, tipo Malaise.
A terminologia adotada na descrição dos caracteres morfológicos foi baseada nos trabalhos de McAlpine (1981), Sinclair (1994) e Cumming et al. (1995).

As terminálias masculinas foram maceradas em acido lático a quente de acordo com Cumming (1992) e examinadas em lâmina escavada com glicerina. As partes dissecadas foram acondicionadas em microtubos plásticos com glicerina que foram alfinetados, através da cortiça, junto ao espécime.

Para serem fotografadas, as asas foram mergulhadas em xilol e montadas com bálsamo em microlâmina. A esta foi colado um pedaço de cartolina para que pudesse ser alfinetada junto ao espécime.

No "Material examinado", os dados de cada etiqueta estão separados por barra (/) e as informações entre colchetes [] completam dados omitidos nas mesmas. Os tipos primários estão depositados no Instituto Nacional de Pesquisas da Amazônia (INPA), Manaus e parátipos no INPA, Museu Paraense Emílio Goeldi (MPEG), Belém, Pará e Museu de Zoologia da Universidade de São Paulo (MZSP), São Paulo, conforme discriminado sob cada espécie.

\section{RESULTADOS}

\section{Porphyrochroa elongata sp. $\mathrm{n}$.} (Figs. 1-8, 27)

Diagnose: P. elongata sp. n. difere de todas as outras espécies conhecidas pelo apódema ejaculador extremamente desenvolvido.

Descrição (holótipo o ${ }^{x}$ ): Olhos dicópticos; omatídios 
subiguais. Fronte e face castanhas, brilhantes. Fronte levemente mais larga que a largura do ocelo inferior, de lados subparalelos, com uma cerda proclinada entre o ocelo inferior e as antenas. Face levemente mais comprida que a fronte e cerca de metade da largura da fronte. Probóscide castanha, tão larga quanto à altura da cabeça. Palpo castanho com uma cerda apical pequena e delgada. Ocelos castanho-claros, vítreos; 2 cerdas ocelares proclinadas; 2 cerdas pós-ocelares proclinadas. Antena com escapo, pedicelo e flagelo castanhos; escapo e pedicelo com cerdas ao redor; flagelo cerca de 4 vezes o comprimento do escapo e pedicelo juntos. Pós-crânio preto, brilhante, com espessa pruinosidade cinza mais concentrada dorsalmente; 2 cerdas verticais internas paralelas; cerdas pósoculares castanhas, distintas, dispostas em unisérie completa, sendo a dorsal mais forte; cerdas pós-craniais distintas, castanhas. Gena e pós-gena com cerdas castanhas a pretas e pruinosidade cinza e esparsa.

Tórax castanho, brilhante, com pruinosidade cinza conspícua e esparsa; 3 cerdas catatergitais delgadas; 4 cerdas escutelares, o par interno maior; cerda antepronotal quebrada (1 no parátipo); cerda pré-episternal quebrada (1 no parátipo); 3 cerdas pós-pronotais, sendo 2 curtas e fracas e 1 longa e forte; 2 cerdas acrosticais anteriores; 4 cerdas dorsocentrais; 1 cerda supra-alar pré-sutural; 1 cerda supra-alar pós-sutural; 2 cerdas notopleurais; 1 cerda pós-alar. Pernas com coxas, trocânteres e 1/5 basal dos fêmures amarelos, o restante castanho. Perna posterior com cerdas longas e delgadas na tíbia; tarsômero basal das pernas média e posterior com pelo menos 5 espinhos longos e fortes ântero-ventrais. Todas as pernas com cerdas de revestimento distintas e curtas.

Asa hialina com pterostigma castanho evidente e lobo anal largo (Fig. 27). Halter castanho.

Abdômen castanho-escuro, brilhante, com reflexo metálico verde em diferentes ângulos de incidência de luz. Esternitos castanhos, brilhantes. Tergitos 6, 7 e 8 subretangulares (Fig. 7). Esternito 8 dividido longitudinalmente em duas placas estreitas amplamente separadas (Fig. 8). Cerco alongado em vista lateral, com depressão no centro (Fig. 1) e com a base mais larga que o ápice (Fig. 5). Hipândrio muito reduzido (Figs. 1 e 3). Apódema ejaculador grande, atingindo o nível do sexto segmento abdominal quando dissecado (Fig. 1); em vista anterior como na figura 4. Epândrio retangular com curta projeção ântero-ventral e região mais escura anteriormente (Fig. 2). Esclerito subepandrial com as larguras da base e do ápice proporcionais (Fig. 6).

Comprimento do holótipo $\sigma^{\pi}$, coletado em álcool: corpo com $3,5 \mathrm{~mm}$; asa $3,4 \mathrm{~mm}$

Fêmea: desconhecida.

Registro geográfico: BRASIL (Amazonas, Acre).

Material examinado: Holótipo. BRASIL, Amazonas, Tabatinga, 11-14.vii.1991 (Etiqueta branca, retangular, impressa)/ Socorro \& Vidal, Varredura (Etiqueta branca, retangular, impressa) / Holótipo macho Porphyrochroa elongata (INPA) (Etiqueta vermelha, retangular, manuscrita).

Parátipos: BRASIL, Amazonas, Tabatinga, 11-14.vii.1991, Socorro

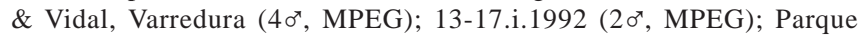

Nacional Jaú, Novo Airão, 11-30.x.1993, J. F. Vidal (40, MPEG);

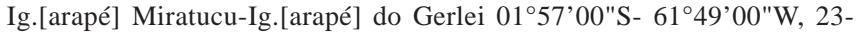
28.vii.1995, Malaise, J. A. Rafael \& J. Vidal (20*, MPEG); Rio Unini,

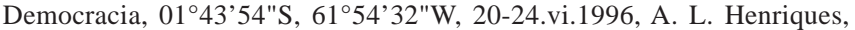
J., Vidal \& F. L. Oliveira, Arm. [adilha] Malaise ( $3 \sigma^{\star}$, MZSP); Carabinani, 27.iv-3.v.1995, Varredura, J. A., Rafael \& J. Vidal (1 $\sigma^{\pi}$, MZSP); Manaus, Reserva Ducke, Varredura, Heliconia, 13.x.1992, Jailson Vidal (10 ${ }^{\star}$, INPA); 16-17.iii.1993, Varredura, Orla, Mata, João Vidal (20" INPA); 04.v.1989, J.A. Rafael \& Socorro Rosa, Flor de Miconia nervosa (10 INPA); 08.vi.1989 (1 $\sigma^{\star}$, INPA); 26 Km NE, R. Ducke, 12.i.1989, J. A. Rafael, Arm. Suspensa, 30 metros (10 $0^{x}$ INPA); S. [anta] Izabel Rio Negro, Maturacá, 11-13.x.1990, Arm. Malaise, J. A. Rafael (1 $0^{\star}$, INPA); Novo Aripuanã, $05^{\circ} 15^{\prime} 53^{\prime \prime} S, 60^{\circ} 07^{\prime} 08^{\prime \prime} \mathrm{W}$, R. Soka 28.iv-05.vi.1999, Cols. Ferreira, R. L.; Rocha, R. A., Vidal, J. \& Leite, R. S., Suspensa alta - área aberta (1 $\sigma^{x}$, INPA); PDBFF-WWF, Proj.[eto]: Bert Klein, i.1985, Malaise, Reserva 1112, xi.1984 (1 $\sigma^{*}$, INPA); Reserva 1113, v.1986 (1 $\sigma^{*}$, INPA); Reserva 1208, i.1985 (1 $0^{*}$, INPA); Reserva 1210, iii.1985

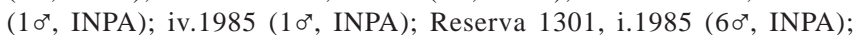

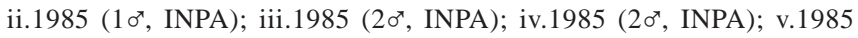

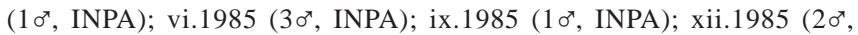
INPA); i.1986 (1 $\sigma^{\pi}$, INPA); iii.1986 (1 $\sigma^{\pi}$, INPA); Acre, Cruzeiro do Sul, Rio Moa, $07^{\circ} 37^{\prime} 02^{\prime \prime} \mathrm{S}-72^{\circ} 46^{\prime} 15^{\prime \prime} \mathrm{W}, 19-28 \times x i .1996$, Varredura, Mata, J. A. Rafael, J. Vidal, \& R. L. Menezes (1 $\sigma^{\pi}$, INPA).

Condição do holótipo: Tíbia e tarso posteriores esquerdos perdidos. Asa esquerda montada em microlâmina; abdômen em vidrinho com glicerina. Microlâmina e microtubo alfinetados junto ao espécime.

Variação: Dois espécimes com uma veia transversal $\mathrm{m}_{1}-\mathrm{m}_{2}$ extra, sendo esta característica uma anomalia.

Etimologia: do Latim elongatus = longo. Refere-se ao longo apódema ejaculador.

\section{Porphyrochroa hipandriociliaris sp. $\mathbf{n}$.}

(Figs. 9-17, 28)

Diagnose: P. hipandriociliaris sp. $\mathrm{n}$. difere de todas as outras espécies conhecidas pela grande quantidade de cerdas na região posterior do hipândrio.

Descrição (holótipo ơ): olhos dicópticos; omatídios subiguais. Fronte e face pretas, brilhantes. Fronte levemente mais estreita que a largura do ocelo inferior, de lados subparalelos. Face levemente mais comprida que a fronte e cerca de metade da largura da fronte. Probóscide castanhoclara, da mesma altura da cabeça. Palpo castanho com uma cerda pequena e delgada apicalmente. Ocelos amarelo-claros, vítreos; 2 cerdas ocelares proclinadas; 2 cerdas pós-ocelares proclinadas. Antena castanha; flagelo cerca de 4 vezes o comprimento do escapo e pedicelo juntos. Pós-crânio preto, brilhante, com espessa pruinosidade cinza mais concentrada dorsalmente; 2 cerdas verticais internas paralelas; cerdas pósoculares distintas, dispostas em unisérie completa; cerdas póscraniais distintas, castanhas. Gena e pós-gena com cerdas castanhas a pretas e pruinosidade cinza e esparsa.

Tórax castanho, brilhante, com pruinosidade cinza conspícua; 3 cerdas catatergitais delgadas; 4 cerdas escutelares; 2 cerdas pós-pronotais; cerdas antepronotais e pré-episternais quebradas; 1 cerda acrostical anterior; 4 cerdas dorsocentrais; cerda supra-alar pré-sutural quebrada, 2 cerdas pós-suturais; 2 cerdas notopleurais; 1 cerda pós-alar. Pernas 


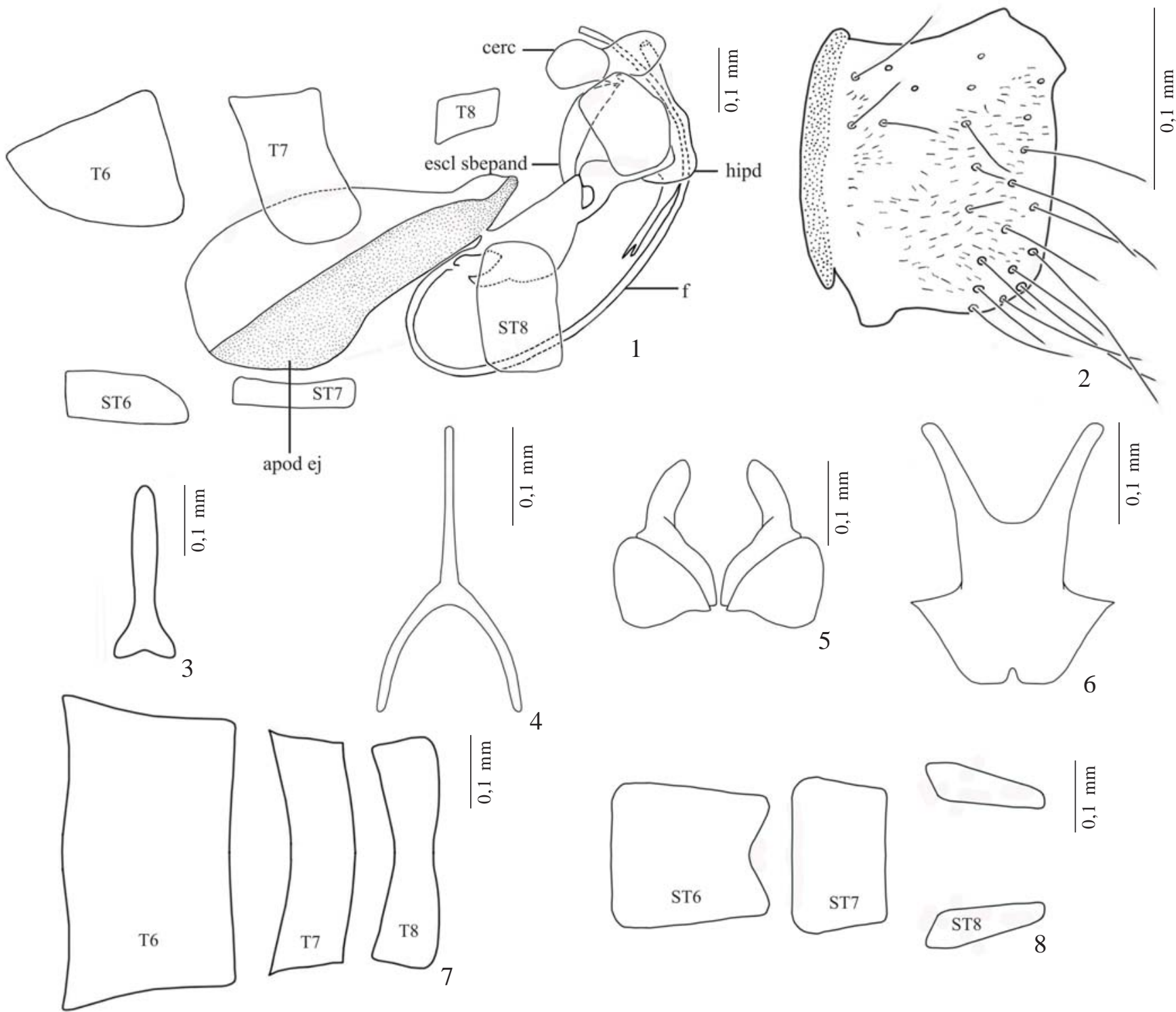

Figs. 1-8. Porphyrochroa elongata sp. n., holótipo ơ: 1, Tergitos 6, 7 e 8, vista dorsal (cerdas não representadas); 2, Esternitos 6, 7 e 8, vista dorsal (cerdas não representadas); 3, Terminália, vista lateral; 4, Epândrio, vista lateral esquerda; 5, Hipândrio, vista posterior; 6, Apódema ejaculador, vista anterior; 7, Cerco, vista dorsal; 8, Esclerito subepandrial, vista ventral. Abreviaturas: apod ej = apódema ejaculador; cerc = cerco; escl sbepand $=$ esclerito subepandrial; $\mathrm{f}=$ falo; hipd $=$ hipândrio; $\mathrm{ST}=$ esternito; $\mathrm{T}=$ tergito.

amarelas com tarsos castanhos; cerdas de revestimento distintas e curtas.

Asa hialina, com pterostigma pouco distinto, célula dm pequena e lobo anal estreito. Veia $\mathrm{R}_{2+3}$ com curva pouco acentuada (Fig. 28). Halter castanho.

Abdômen castanho-escuro, brilhante, com reflexo metálico verde em diferentes ângulos de incidência de luz. Esternitos castanho-escuros, brilhantes. Tergito 7 com protuberância póstero-ventral; Tergito 8 mais largo que os precedentes (Fig. 9). Esternito 8 largo (Fig. 10); esternito 6 e 7 inclinados em vista lateral (Fig.11). Cerco alongado e largo em vista lateral (Fig. 11); em vista dorsal com ápice arredondado e projeção basal interna direcionada para baixo e para trás (Fig. 16). Hipândrio, falo e apódema ejaculador como na figura 12 .
Hipândrio com cerca de 40 cerdas na região posterior (Figs. 12,13). Epândrio subtriangular projetado ventralmente e com cerdas longas distalmente (Fig. 14). Apódema ejaculador com três projeções, em vista anterior (Fig. 15). Esclerito subepandrial alongado (Fig. 17).

Comprimento do holótipo ${ }^{\pi}$, coletado em álcool: corpo 2,4 $\mathrm{mm}$; asa 2,3 $\mathrm{mm}$.

Fêmea: desconhecida.

Registro geográfico: BRASIL (Amazonas).

Material examinado: Holótipo. BRASIL, Amazonas, Querari (Pelotão), $01^{\circ} 05^{\prime} \mathrm{N}-69^{\circ} 51^{\prime} \mathrm{W} /$ (Etiqueta branca, retangular, impressa) 06.iv-15.v.193, João Vidal (Etiqueta branca, retangular, impressa)/ Holótipo macho Porphyrochroa hipandriociliaris (INPA) (Etiqueta vermelha, retangular, manuscrita). 

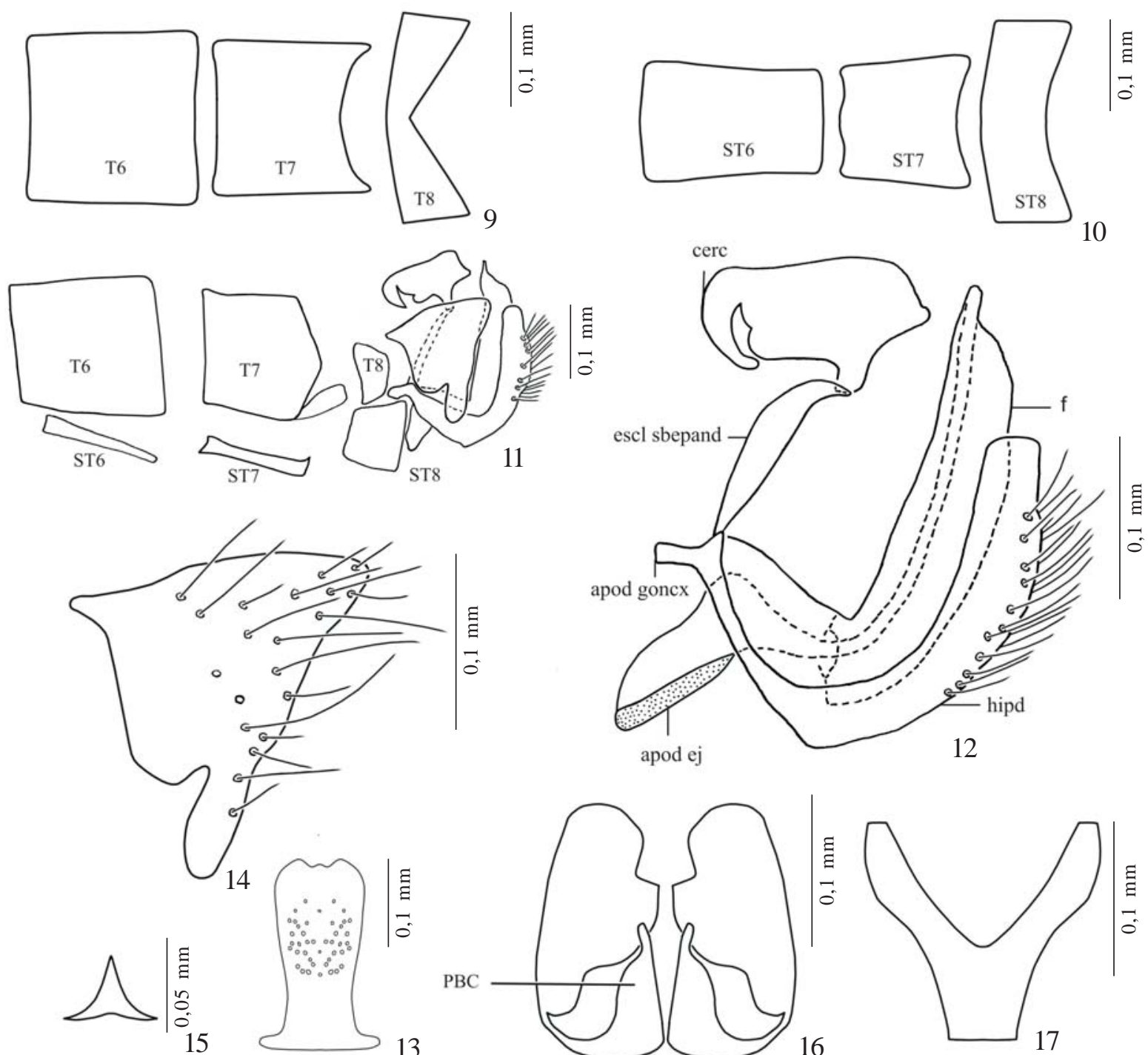

15
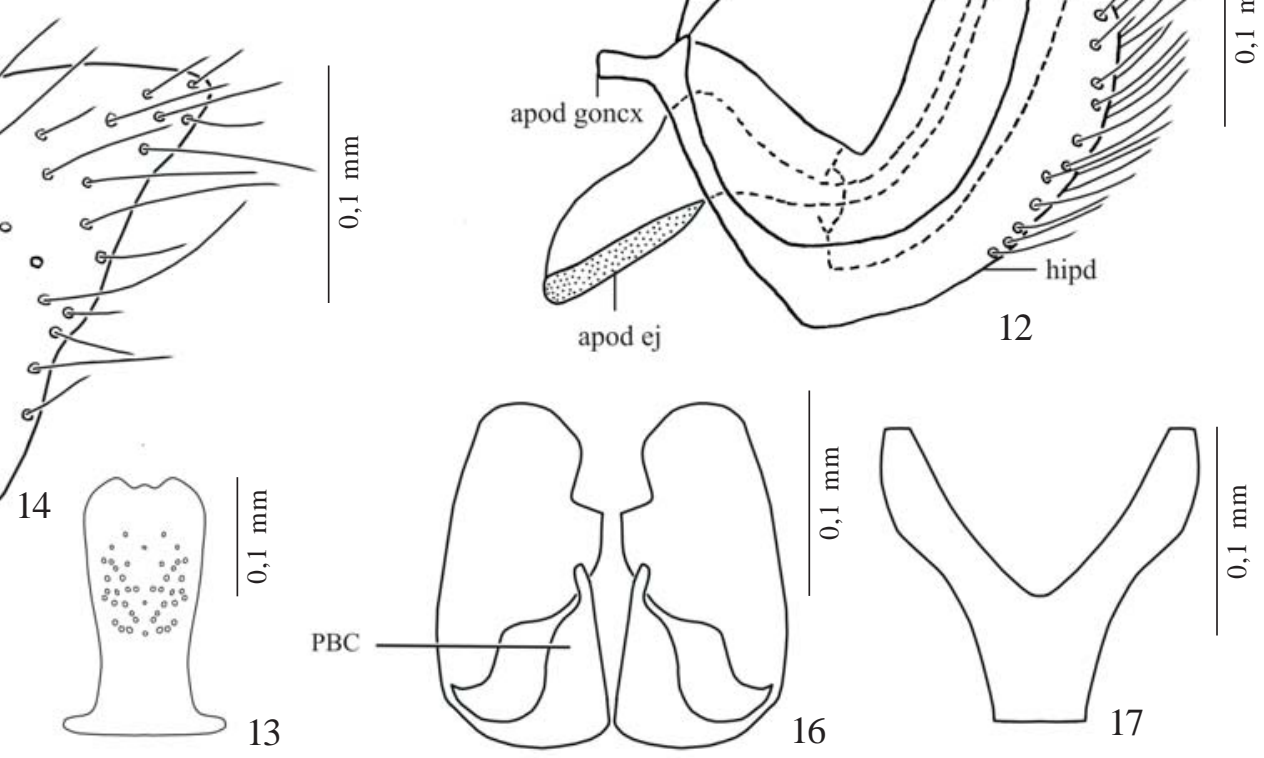

Figs. 9-17. Porphyrochroa hipandriociliaris sp. n., holótipo ơ: 9, Tergitos 6, 7 e 8, vista dorsal (cerdas não representadas); 10, Esternitos 6, 7 e 8, vista dorsal (cerdas não representadas); 11, Terminália, vista lateral; 12, Hipândrio, falo, cerco e esclerito subepandrial, vista lateral; 13, Hipândrio, vista posterior; 14, Epândrio, vista lateral esquerda; 15, Apódema ejaculador, vista anterior; 16, Cerco, vista dorsal; 17, Esclerito subepandrial, vista ventral. Abreviaturas: apod ej = apódema ejaculador; apod goncx = apódema gonocoxal; cerc $=$ cerco; escl sbepand $=$ esclerito subepandrial; $\mathrm{f}=$ falo; hipd = hipândrio; $\mathrm{PBC}=$ projeção basal do cerco; $\mathrm{ST}$ = esternito; $\mathrm{T}$ tergito.

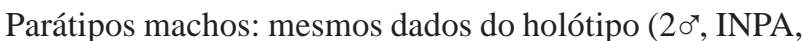
$10^{x}$, MPEG).

Condição do holótipo: pernas posteriores perdidas; antena com flagelos quebrados; asa esquerda montada em microlâmina; abdômen em microtubo com glicerina. Microlâmina e microtubo alfinetados junto ao espécime.

Variação: Um parátipo com fêmur e tíbia posteriores castanhos.

Etimologia: do Latim cilium = cerda, cílio. Refere à presença de muitas cerdas na parte posterior do hipândrio.

\section{Porphyrochroa vidali sp. $\mathrm{n}$.}

(Figs. 18-26, 29)

Diagnose: $P$. vidali sp. n. é próxima de $P$. argentata por possuirem quatro projeções no apódema ejaculador, em vista anterior. Difere da mesma pela ausência de projeções posteriores no esternito 6 e pela presença de cerdas no hipândrio.

Descrição (holótipo ơ ): olhos dicópticos; omatídios subiguais. Fronte e face castanhas, brilhantes. Fronte levemente mais estreita que a largura do ocelo inferior, de lados subparalelos. Face levemente mais comprida que a fronte e cerca de metade da largura da fronte. Probóscide amareloclara, tão larga quanto à altura da cabeça. Palpo castanho com uma cerda apical pequena e delgada. Ocelos amarelo-claros, vítreos; cerdas ocelares proclinadas e longas; cerdas pósocelares proclinadas e curtas, cerca de $1 / 3$ o tamanho das cerdas ocelares. Antena com escapo, pedicelo e flagelo 

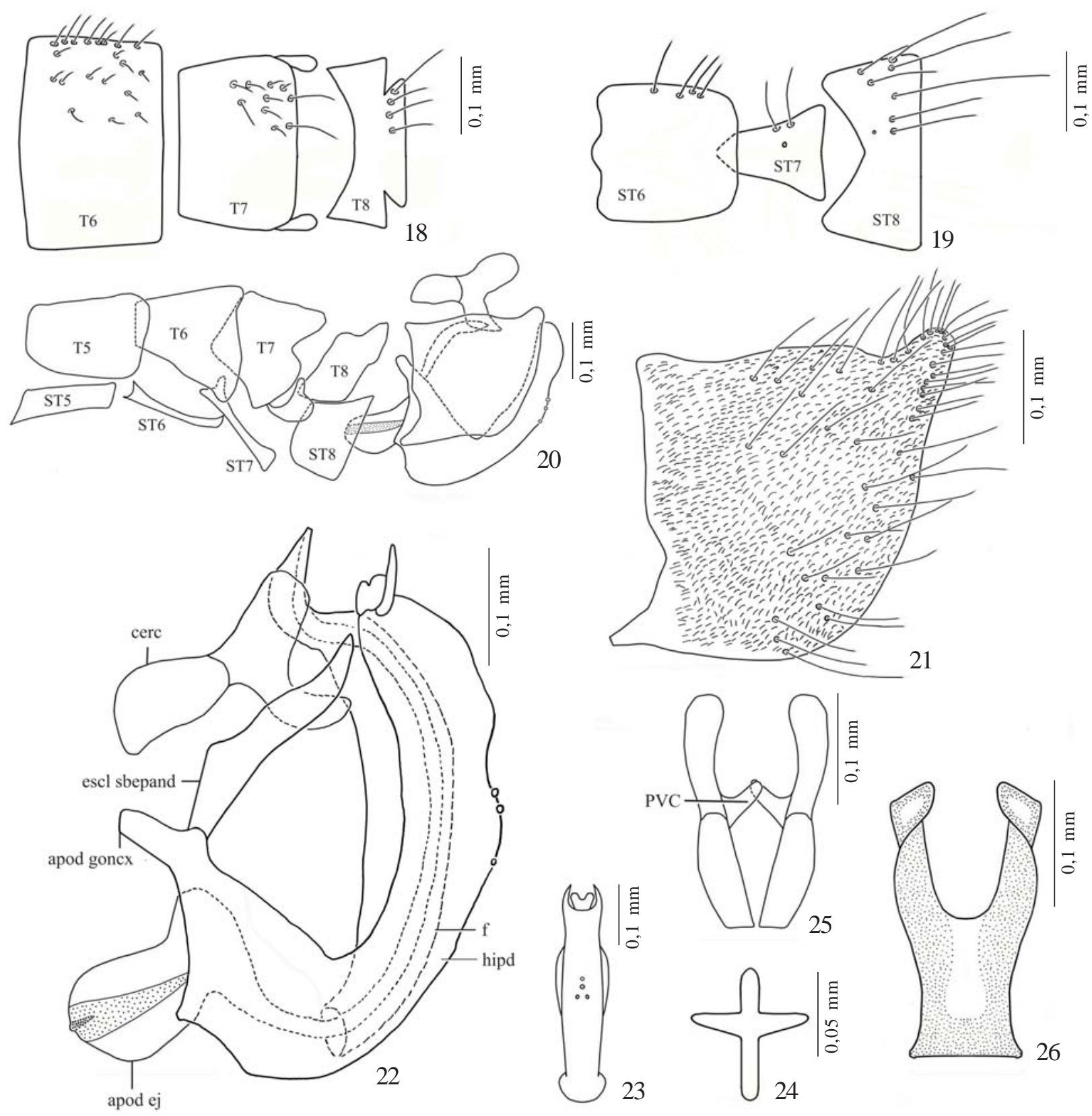

Figs. 18-26. Porphyrochroa vidali sp. n., holótipo ơ: 18, Tergitos 6, 7 e 8, vista dorsal; 19, Esternitos 6, 7 e 8, vista dorsal; 20, Terminália, vista lateral; 21, Epândrio, vista lateral; 22, Hipândrio, falo, cerco e esclerito subepandrial, vista lateral; 23, Hipândrio, vista posterior; 24, Apódema ejaculador, vista anterior; 25, Cerco, vista dorsal; 26, Esclerito subepandrial, vista ventral. Abreviaturas: apod ej $=$ apódema ejaculador, apod goncx = apódema gonocoxal, cerc $=$ cerco, escl sbepand $=$ esclerito subepandrial, $\mathrm{f}=$ falo, hipd $=$ hipândrio, PVC = projeção ventral do cerco, ST $=$ esternito, $\mathrm{T}=$ tergito

castanhos; flagelo cerca de 4 vezes o comprimento do escapo e pedicelo juntos. Pós-crânio castanho, brilhante, com espessa pruinosidade cinza mais concentrada dorsalmente; 1 par de cerdas verticais internas convergentes; cerdas pós-oculares distintas, dispostas em unisérie completa, sendo a dorsal mais forte; cerdas pós-craniais distintas, castanhas. Gena e pósgena com cerdas castanhas a pretas e pruinosidade cinza e esparsa.

Tórax castanho, brilhante, com pruinosidade cinza conspícua e esparsa; 3 cerdas catatergitais delgadas; 4 cerdas escutelares, o par interno maior; cerdas antepronotais e préepisternais quebradas; 1 cerda pós-pronotal; 2 cerdas acrosticais anteriores; 4 cerdas dorsocentrais; 1 cerda supraalar pré-sutural; 1 cerda supra-alar pós-sutural; 1 cerda notopleural; 1 cerda pós-alar. Perna anterior, média e posterior, com coxas, trocânteres e 1/5 basal dos fêmures, amarelos, o restante castanho. Todas as pernas com cerdas longas e espaçadas; cerdas de revestimento distintas e curtas.

Asa castanha com pterostigma inconspícuo entre o final de $\mathrm{R}_{1}$ e o final de $\mathrm{R}_{2+3}$; lobo anal largo (Fig. 29). Halter castanho. 

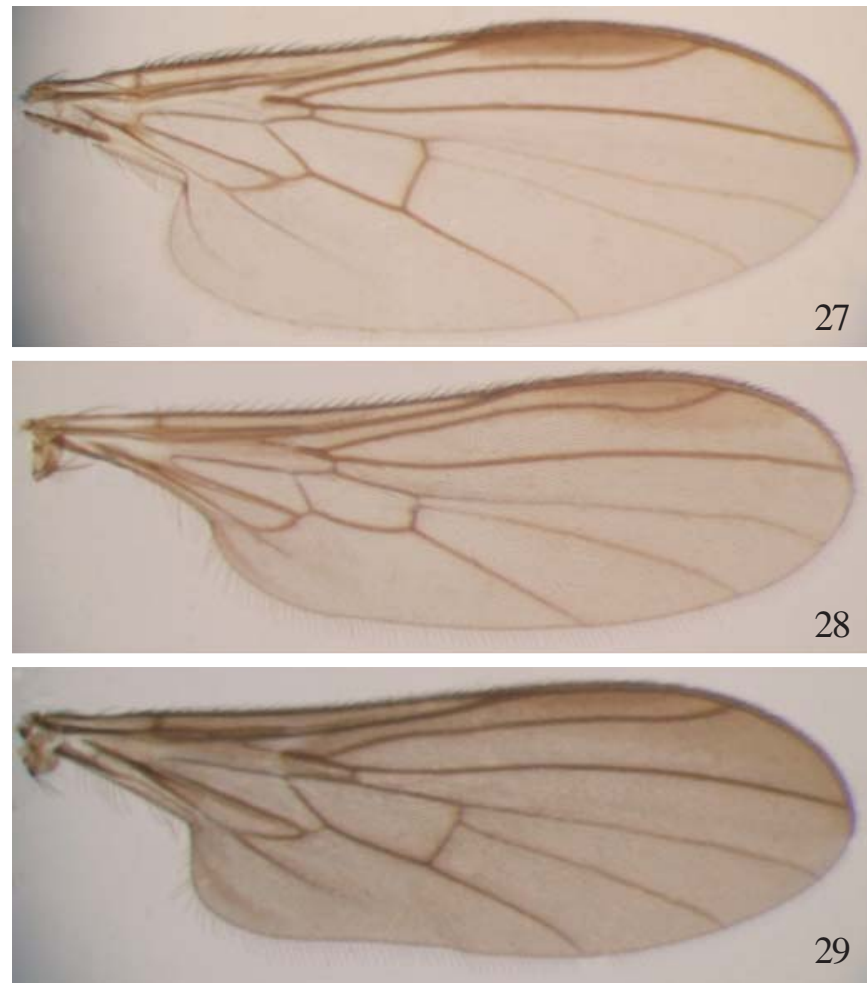

Figs. 27-29. Asas esquerdas de Porphyrochroa (Diptera, Empididae), holótipo ơ; 27, Porphyrochroa elongata sp. n.,; 28, Porphyrochroa hipandriociliaris sp. n.; 29, Porphyrochroa vidali sp. n.

Abdômen castanho-escuro, brilhante, com reflexo metálico azul em diferentes ângulos de incidência de luz. Esternitos castanhos. Tergito 7 com protuberância póstero-ventral; tergito 8 com projeção mais estreita no ápice (Fig. 18); esternito 7 pequeno e esternito 8 mais largo que os precedentes (Fig. 19); esternitos 6 e 7 inclinados em vista lateral (Fig. 20). Cerco alongado com projeção ventral dirigida para baixo (Fig. 20, 25). Epândrio largo, com projeção digitiforme, cerdas longas nos $2{ }_{3}$ distais e revestido de microtríquias (Fig. 21). Hipândrio com poucas cerdas (perdidas) e leve sinuosidade posterior, além de duas projeções apicais (Fig. 22); em vista posterior como na figura 23. Apódema ejaculador com 4 projeções em vista anterior (Fig. 24). Esclerito subepandrial com dobra no ápice dos braços (Fig. 26).

Comprimento do holótipo ${ }^{\star}$, coletado em álcool: corpo 2,4 $\mathrm{mm}$; asa 2,6 $\mathrm{mm}$.

Fêmea: desconhecida.

Registro geográfico: BRASIL (Amazonas, Roraima).
Material examinado: Holótipo. BRASIL, Roraima, Rio Auaris, 780 m., $04^{\circ} 00^{\prime} 10^{\prime \prime} \mathrm{N}-64^{\circ} 29^{\prime} 19^{\prime \prime} \mathrm{W}$ (Etiqueta branca, retangular, impressa) / 27-29.v.1995, Arm. [adilha] Malaise, L. Aquino \& F. Fernandez (Etiqueta branca, retangular, impressa) / Holótipo macho Porphyrochroa vidali (INPA) (Etiqueta vermelha, retangular, manuscrita).

Parátipos: BRASIL, Roraima, Xitei (Xidea), 02³6’24"N$63^{\circ} 52^{\prime} 17^{\prime \prime W}$, 20.ix.1995, L. S. Aquino, Arm. Malaise (10 Amazonas, Parque Nacional Jaú, Ig.[arapé] Miratucu - Ig.[arapé] do Gerlei, 0157’00"S-6149'00"W, 23-28.vii.1995, Arm. Malaise, J. A. Rafael \& J. Vidal ( $10^{\star}$, INPA).

Condição do holótipo: asa esquerda montada em microlâmina; abdômen em microtubo com glicerina. Microlâmina e microtubo alfinetados junto ao espécime.

Etimologia: $\mathrm{O}$ nome específico é uma homenagem ao técnico do INPA, João Ferreira Vidal.

Agradecimentos. Ao CNPq pela bolsa de estudo concedida ao primeiro autor.

\section{REFERÊNCIAS}

Cumming, J. M. 1992. Lactic acid as an agent for macerating Diptera specimens. Fly Times, Ottawa, 8: 7.

Cumming, J. M.; B. J. Sinclair \& D. M. Wood. 1995. Homology and phylogenetic implications of male genitalia in Diptera Eremoneura. Entomologica Scandinavica 26: 120-151.

McAlpine, J. F. 1981. Morphology and terminology - Adults [Chapter] 2. In: McAlpine, J. F.; B. V. Peterson; G. E. Shewell; H. J. Teskey; J. R. Vockeroth \& D. M. Wood. (Coords.), Manual of Neartic Diptera, Volume 1. Agriculture Canada Monograph 27: 9-63.

Melander, A. L. 1928. Diptera, Fam. Empididae. In: P. Wytsman (Ed.). Genera Insectorum. Fascicule 185. Bruxelles, Louis DesmetVerteneuil, 434p. [1927].

Rafael, J. A. 2001. Redescrição de duas espécies neotropicais de Empididae (Diptera) descritas por Curran e revalidação do gênero Prophyrochroa. Iheringia, Série Zoologia, Porto Alegre, 90: 127-132.

Rafael, J. A. \& J. M. Cumming. 2004. The Neotropical genera Macrostomus Wiedemann and Porphyrochroa Melander (Diptera, Empididae, Empidinae). Revista Brasileira de Zoologia, 21: 439-448.

Sinclair, B. J. 1994. Revision of Neartic species of Trichoclinocera Collin (Diptera: Empididae; Clinocerinae). Canadian Entomologist, Ottawa, 126: 1007-1059.

Sinclair, B. J. \& J. M. Cumming. 2006. The morphology, higher-level phylogeny and classification of the Empidoidea. Zootaxa 1180: $1-172$.

Smith, K. G. V. 1967. Family Empididae (Empididae, Hybotidae) [Part] 39. In: A Catalogue of the Diptera of the Americas south of the United States. São Paulo, Departamento de Zoologia, 67p. 